\title{
Editorial
}

\section{Resilience 2011: Leading Transformational Change}

\author{
Lance Gunderson $^{1}$ and $\underline{\text { Carl Folke }}^{2}$
}

Change is inevitable - except from a vending machine.

Robert C. Gallagher

\section{INTRODUCTION}

Hundreds of researchers, practitioners, and others gathered this past March in Phoenix, Arizona for the second international conference on resilience science and policy. Organized by Marty Anderies and Sander van der Leuw, and other Arizona State University faculty, the week-long conference focused on integrating understanding among three research communities, all of whom work in coupled social-ecological systems. The first is the resilience network, the second group develops sustainability science, and the third group studies innovation. The conference themes of adaptation and vulnerability, thresholds and regime shifts, knowledge and learning, governance and scales, development and resources, and transformation were addressed in hundreds of presentations. Although some of the presented studies and information has been published in this journal, we invite others to share their results in future submissions. We also would like to thank the organizers and participants for their efforts and hard work that resulted in this highly successful meeting.

One of the major unanswered themes at the meeting was the gap between science and policy that seems to be widening in many places. In more practical or basic terms, what is the relevance of resilience scholarship to practical issues? This is a very difficult question, and unlikely to be resolved in one meeting, let alone a small editorial. However, we argue that even though this gap may be widening and becoming more uncertain, the need to span it is increasing. Witness the global changes that have happened in the past six months.
Our world is transforming at an alarming pace. Though only half of the year 2011 has occurred, it has already been a dramatically dynamic year, with multiple crises per month. Following a severely cold winter in the northern hemisphere, the spring has brought unprecedented changes. The tsunami in Japan that occurred during the Resilience 2011 conference, and the Arab spring, with massive social upheaval, were transformative events with global repercussions. In the U.S. alone, there have been at least seven environmental disasters, including ice storms, tornadoes, droughts, fires, floods in major rivers, each of which has been estimated to result in over one billion dollars of damage. With these types of events recurring, it is no surprise that resilience is becoming a commonly applied word. But is it making a difference? We think the answer depends on the geographic scale at which the question is asked.

The overwhelming conclusion from Resilience 2011 is that at local and perhaps regional scales, the scholarship is transforming the way in which we think, understand, and manage our world. From water management in Asia, to the Sahel in Africa, to native communities in Canada, to forests in South America, to islands in the great oceans of the world, resilience-based approaches are guiding better stewardship and learning-based approaches. Whether these ideas will scale up and actually affect decisions at the planetary scale is an open question, but we remain optimistic.

During the spring, The Economist (May 28th issue) wrote about the Anthropocene, the new geological era or age-of-man that we are now in and for which resilience thinking is central. In May, the third Nobel Laureate Symposium on Global Sustainability, Transforming the World in an Era of Global Change, was held in Stockholm, with a strong resilience focus (www.globalsymposium2011.org). The symposium gathered some 50 invited participants, i.e., 
Nobel Laureates, experts on sustainability and resilience, high-level representatives of politics, civil society, and business. Three major syntheses: of social-ecological resilience and reconnecting development to the biosphere; of the anthropocene, planetary boundaries and stewardship; and of social innovation for transformations toward global sustainability (forthcoming in Ambio) set the stage for the discussions with a memorandum generated by the participants. The UN High Level Panel on Global Sustainability, chaired by the Presidents of Finland and South Africa, joined the meeting the last day. The Stockholm Memorandum, Tipping the Scales towards Sustainability, signed by the Nobel Laureates, was handed over by the Permanent Secretary of the Royal Swedish Academy of Sciences to the UN Panel as input to their work for the Rio+20 conference in 2012. The memorandum is rapidly spreading worldwide with well over 20,000 web-reports as of date.

\section{THIS ISSUE}

In the meantime, the scholarship continues, reflected by the contributions to the two first issues of 2011 of Ecology and Society. During the first six months of this year we have published over 80 peerreviewed articles. These two issues contain regular articles, of which 57 are research articles, 13 are synthesis and perspective articles, nine are insight articles, and two are responses to previous articles. We continue to feel very pleased with the strong interactions between the ecological and social components of all the contributions, with a clear emphasis on integrative science for resilience and sustainability. Many new journals are emerging addressing social and ecological issues in a sustainability context, but we find that we very much have a unique focus here with many contributions at the very front of understanding interdependent social-ecological systems.

It is not an easy task to give justice to over 80 contributions in an editorial, but an attempt to capture the focus follows. Several articles contribute to resilience theory, beautifully combining the empirical with the theoretical, the inductive with the deductive. Work combines periods of gradual and rapid change, panarchy, resilience, and transformability in e.g., Central Asia, Mexico, Germany, Italy, and the Netherlands and expands into related fields.
The Ecology and Society tradition with networks, innovation, leadership, agency in relation to socialecological resilience are at the forefront in several contributions. Learning, drawing on diverse knowledge systems and diverse mental models, models and approaches for participation, collaborative transdisciplinary arenas, handling uncertainty and risk in policy development, and other features of adaptive governance are in focus in several papers.

Several deal with adaptive management, collective action, and governance of social-ecological systems in landscapes and marine systems, some focusing on reflexivity and transitions, others on policies and incentives in fisheries, forestry, agriculture, and water and wildlife management. Others develop indicators and diagnostics, investigate the scale issues and mismatches between institutions and ecosystems, and connect social-ecological resilience to health and well-being and local to global actions.

Livelihood, gender issues, compliance, and conflicts in relation to forest ecosystem services, and key factors of adaptive capacity in their stewardship are captured in a handful of papers. Vulnerable peoples, regions, industries, as well as fisheries collapses and disaster management are the focus of some contributions. Others deal with social-ecological disturbances and their management as well as the significance of biological diversity in resilience and insurance. A set of papers addresses scenarios as part of adaptive strategies for ecosystem services, and assessments of global challenges and crises including biodiversity loss. Some broaden the diversity issue by focusing on social diversity in water management.

There are also those that draw on long-term archeological studies of social-ecological traps and transformations and those that emphasize cultural features of resilience and traditional knowledge systems in stewardship. An interesting paper introduces the concept of social-ecological guilds into long-term marine issues.

Straightforward contributions include adaptation and transformation in relation to energy issues and their markets, policies, and also water links, as well as economic drivers and benefits of ecosystem stewardship and cumulative effect social indicators. Our special features continue to be a hallmark of the journal, and note that 42 of the published articles are part of a special feature. We highlight the 
contributions of four special features that are now finalized.

Two were part of the first issue of 2011, both focusing on the landscape level. The first, Landsca pe Scenarios and Multifunctionality - Making Land Use Assessment Operational, edited by Katharina Helming and Marta Pérez-Soba, presents nine papers dealing with the needs and uses of assessment tools for policy making at the European level. The concept of landscape multifunctionality was applied for integrating the socioeconomic with the biogeophysical with findings emphasizing: the involvement of decision makers early on in the design of the impact assessment study; the integration of quantitative analysis with participatory valuation methods; and the robust and transparent design of the analytical methods.

The second special feature, Effects of Roads and Traffic on Wildlife Populations and Landscape Function, edited by Rodney van der Ree, Jochen A. G. Jaeger, Edgar A. van der Grift, and Anthony P. Clevenger, documents the effects of roads and traffic on wildlife. The 17 papers, from Australia, Canada, the Netherlands, and USA, all deal with population or community-level effects, while higher order effects have been difficult to capture. The editors conclude that road ecology research would benefit from combining multiple road projects studied as part of integrated, wellreplicated research projects.

The second issue also presents two features now focusing on the scale issue. The first, $\underline{\text { Scale and Go }}$ vernance, edited by Kasper Kok and Tom Veldkamp, presents three scoping papers, providing a state-of-the-art overview of the conceptual discussion on the hotly debated area of scale and governance, and six case study papers that set out to deal with the practicalities of their combination. The scoping papers underline that a complex systems and social-ecological system approach is needed to improve the understanding of scale and governance, but the case study papers illustrate that the conceptual advances have not been taken up to their full extent in practice. They conclude that transdisciplinary arenas are required where the concepts of scale and governance are framed such that a broad variety of stakeholders can join the debate and/or the decision making process.

The final special feature deals with Long-Term Vu Inerability and Transformation, and is edited by
Christo Fabricius and Michael Schoon. Founded on a long-term archeology perspective, the six papers analyze how societal choices are influenced by robustness, i.e., vulnerability trade-offs and the interplay between robustness, vulnerability tradeoffs and robustness, and performance trade-offs, with societies often locked in to particular strategies, reinforced by multiple positive feedbacks that escalate the perceived cost of societal change. How can such lock-in traps be prevented or the risks associated with them be mitigated? They conclude by highlighting how long-term historical studies can help understand current society, societal practices, and the nexus between ecology and society.

We wish the reader exciting moments and new discoveries among the amazing contributions. We are most grateful for the hard work of all that contribute to Ecology and Society. We cannot thank enough the dedicated editors and reviewers who give of their precious time to support this work. We thank the Resilience Alliance for fiscal and administrative support. Finally we thank the staff, Jennifer Miner and Adele Mullie, who have managed the day to day operations, and the copy editors who improve all of our writing, but are rarely acknowledged. We are privileged for the opportunity to edit a journal receiving contributions with the purpose of understanding and helping to navigate an ongoing transformation.

Responses to this article can be read online at: http://www.ecologyandsociety.org/voll6/iss2/art30/ responses/ 